\title{
Territorios de la memoria: La retórica de la calle en Villa Francia
}

\author{
Gabriela Raposo Quintana \\ Universidad Academia de Humanismo Cristiano, Santiago, Chile. Email: gabriela@raposo.cl
}

\begin{abstract}
Resumen: Este artículo aborda la relación entre memoria, identidad y territorio, utilizando como anclaje del argumento las diversas prácticas conmemorativas post-dictadura que se desarrollan en Villa Francia, población emblemática de la ciudad de Santiago. Esta relación se traduce en la ocupación de la calle, en tanto territorio donde la memoria se emplaza, a la vez que es parte misma de los objetos de memorialización. La ocupación de la calle es el resultado de encuentros y desencuentros en el tiempo, que involucran tanto los contenidos de la memoria, como las características materiales y simbólicas de las prácticas conmemorativas que se sostienen en el espacio público. Marginales en forma y contenido de aquellas promovidas por el Estado, estas prácticas interpelan y obligan a girar la mirada hacia la comprensión de la calle como el resultado de lo múltiple, de lo deseado y no deseado, fruto de la acción práctica de la identidad en el territorio.
\end{abstract}

Palabras clave: Memoria, identidad, territorio, Villa Francia

\section{Territories of memory: The rhetoric of the street in Villa Francia}

\begin{abstract}
This paper approaches the relationship between memory, identity and territory, using as vehicle the diverse commemorative practices post-dictatorship developed in Villa France, an emblematic neighborhood of Santiago (Chile). This relationship is translated in using streets as a location where memory is situated as well as it is itself a part of the objects of the memory. The use of streets is the result of encounters and des-encounters through time, which involve the contents of memory as well as the material and symbolic characteristics of the commemorative public-space held practices. These memories, marginal in form and content to those promoted by the State, address and force a turning of the glance towards the comprehension of the street as the result of multiplicity, of that which is wished and not wished, as the result of practical actions of identity within the territory.
\end{abstract}

Key words: Memory, identity, territory, Villa Francia

\section{Territórios da memória: a retórica da rua em Villa Francia}

Resumo: Este artigo discute a relação entre memória, identidade e território, usando como âncora do argumento as várias práticas comemorativas pós-ditadura que acontecem em Villa Francia, bairro emblemático da cidade de Santiago. Esta relação se reflete na ocupação da rua, enquanto território onde a memória está localizada, sendo da mesma forma parte dos objetos de memorialização. A ocupação da rua é o resultado de encontros e desencontros no tempo, envolvendo tanto o conteúdo da memória, como as características materiais e simbólicas das práticas comemorativas realizadas em o espaço público. Sendo marginais em forma e conteúdo desses promovida pelo estado, estas práticas desafiam e requerem rodar a olhadela a fim de compreender a rua como o resultado da múltiplicidade, do desejado e indesejado, resultado da ação prática da identidade no território.

Palavras-chave: Memória, identidade, território, Villa Francia

$$
* * *
$$

\section{Introducción}

Luego del término de la dictadura militar, y siguiendo las tendencias mundiales de los procesos de memorialización guiados por los estados y vinculados a las violaciones de los derechos humanos, comenzaron a desarrollarse en Chile diversas iniciativas conmemorativas. Por parte del Estado, se trata principalmente de la configuración de sitios que han sido proyectados como espacios educativos y de reflexión, así como también de obras simbólicas de conmemoración, tales como placas recordatorias, monumentos memoriales y obras de arte. Sin embargo, alejándose de estas tendencias, existen otras memorias y espacios que han sido producidos por parte de sujetos y colectividades en un proceso de reivindicación que resiste a la institucionalización de la memoria, reinventándola en diversas estrategias conmemorativas que involucran la 
apropiación de los espacios públicos, como una forma de contestación al aparato del Estado, y también porque son expresión de la identidad territorializada de los grupos de actores que promueven estas memorias.

Villa Francia, en Santiago de Chile, es uno de estos espacios. Reconocida como una de las poblaciones más fuertemente golpeadas durante la dictadura militar, con cuatro personas detenidas desaparecidas (1974) y nueve jóvenes asesinados (uno el año 1973 y ocho entre 1984 y1988), hoy es uno de los lugares donde se desarrollan prácticas conmemorativas, que distanciándose del proceso de memorialización institucional, tienden tanto a la recordación de los muertos de la dictadura como a la proyección de sus legados. Ello resulta fundamental de destacar, ya que no se trata de prácticas centradas en el culto a las víctimas, o en la sensibilización respecto del pasado -como ocurre con los sitios de conciencia-, sino que más bien son discursos centrados en la posibilidad de alcanzar un proyecto de sociedad (por el que luchaban las víctimas), y en este sentido la práctica conmemorativa, más que recordación, persigue potenciar una reflexión crítica sobre lo social, lo político y lo económico del presente.

Dentro de este marco, si bien algunas de las prácticas conmemorativas que se desarrollan en Villa Francia coinciden con la memoria propiciada desde el Estado, la mayoría de ellas aparece como la reafirmación constante de oposición a su institucionalidad, disputándose los sentidos de la memoria y los espacios donde ésta puede exteriorizarse. Ello ha posibilitado que la población se configure y re-dibuje a lo largo de los años, como el territorio de una memoria que resiste. En la Villa, la memorialización se manifiesta materialmente como un fenómeno en construcción, emergiendo continuamente intervenciones urbanas cuya constante es la apropiación de la calle, ya sea en rayados de murallas, acciones de protesta, actos conmemorativos, o en la instalación de un memorial. La materialidad efímera de las intervenciones, así como la transitoriedad de los actos públicos, sugieren la posibilidad de una memoria que ha logrado persistir en el tiempo re-significándose, y sirviendo como eje de resistencia frente a la fijación de una memoria institucional, tanto en el espacio como a nivel de contenidos. Las prácticas conmemorativas a su vez, han influido en la conformación identitaria del grupo de actores que participan en ellas, reforzando su capacidad de acción y contestación frente al Estado, caso particular en el cual la reivindicación de la memoria puede traducirse en acción insurgente. Por otra parte, desde mediados de los '90 ha surgido una fuerte visión mediática que ha sindicado a Villa Francia como una población, para algunos conflictiva y violenta, y para otros combativa y comprometida. En la Villa no sólo se disputa la calle, sino que la posibilidad de dejar allí una memoria abierta, distinta de aquella pública reconocida por el Estado.

El texto que se desarrolla a continuación, se encuentra separado en dos apartados. En el primero de ellos se argumenta acerca de la capacidad de acción del discurso identitario en Villa Francia que se construye en torno de la práctica conmemorativa y de cómo éste impacta en la configuración de los territorios simbólicos de la memoria. El segundo apartado, enmarca la importancia que ha tenido la calle en Villa Francia como principal vehículo de memorialización, a la vez que ésta se constituye en un elemento fundamental en la configuración de una identidad territorializada. Al término del documento se realizan algunas consideraciones finales.

\section{La acción del discurso identitario y los territorios simbólicos de la memoria}

La ciudad, propone Márquez (2008), es el lugar de la experimentación, de la diferencia y del movimiento, es donde se forjan distintos deseos e imaginarios que hacen de este espacio, un territorio en disputa. Espacios residuales se abren en el transcurrir de la ciudad, dando cabida a distintas narrativas identitarias, aquellas que surgen entre la distancia que genera la diferencia entre los modos de habitar y los modos de imaginar los espacios de la ciudad, provocando que ellos se tornen en un campo en fricción, lugares de resistencia y de conflicto. Ampliando estos modos de imaginar, no sólo al espacio urbano sino que a la realidad y sus significaciones, Reguillo (1991) propone que la ciudad es el espacio en disputa donde se enfrentan las distintas visiones de mundo que allí emergen, porque la ciudad es experimentada desde diversas posiciones, relaciones sociales y simbólicas, cada una con sus propias narrativas.

Algunas de estas narrativas son sostenidas por colectividades que comparten su pertenencia hacia territorios (apropiados y simbólicos) y grupos sociales, donde los distintos miembros tienen en común lenguajes, historias, consumo cultural, entre otros, conformando una identidad. El discurso o narrativa 
identitaria (Reguillo, 1991; Bengoa, 2011 y Márquez, 2008) define y distingue al grupo, haciendo que sus miembros se identifiquen y reconozcan, tomando consciencia de sí mismos, y posibilitándoles distinguirse de otros grupos e individuos (alteridad). Su función es objetivar la visión de mundo que la colectividad propone, incorporando argumentos respecto de la realidad presente, los significados que dan sentido a esa realidad, así como también elementos de la memoria del grupo. En este marco, la identidad se configura sobre una selección de fragmentos que han sido tomados desde el pasado y el presente, en vías de elaborar un discurso vigente y coherente que reafirme a la colectividad.

Uno de los rasgos principales de todo discurso identitario es su capacidad de acción (Márquez, 2008; Bajoit, 2003; Bengoa, 2011 y Reguillo, 1991 y 1996). Esto es, el saber-ser mediante actos prácticos y simbólicos (Márquez, 2008), tanto como el saber-hacer, ya que es esta fuerza material para realizar cosas y exteriorizarse, lo que le otorga a la narrativa identitaria un rostro social (Reguillo, 1996). La configuración de este discurso es necesaria para que el grupo pueda reafirmarse, no perder legitimidad y sostenerse en el tiempo, proyectando su futuro y construyendo su propia historia. Dentro de este marco, la capacidad de acción -mostrarse y visibilizarse-, es de acuerdo a Reguillo (1991), la forma en la cual la identidad se objetiva. Ésta puede ser entendida "como redes de comunicación desde donde se procesa y se difunde el mundo social [de un grupo]" (Reguillo, 1996:56), y desde las cuales la identidad se manifiesta frente a los otros, representándose y haciéndose real. Dado lo anterior, la capacidad de acción fundada entre el saber-ser y el saber-hacer de la identidad en el territorio, es también poder político en tanto revela su potencialidad para argumentar, intervenir o transformar los espacios donde se llevan a cabo y proyectan las acciones.

El espacio público es por excelencia la esfera de la ciudad en la cual se muestran y circulan las diversas narrativas identitarias. En la práctica socio-espacial de los distintos grupos de actores, estos discursos irrumpen repoblando la ciudad a partir de las acciones que allí tienen cabida, dejando tanto huellas materiales como simbólicas, muchas veces de una gran potencia enunciativa. Cuando la narrativa identitaria se fija en el espacio, éste deviene territorio, es decir, el espacio que da "forma y sentido a la vida del grupo" (Reguillo, 1996:78), y que ha sido apropiado ya sea a través de la acción transformadora que se refleja en prácticas concretas, o bien, a partir de la identificación simbólica; apropiación que tiene como resultado espacios significados, pertenencia e identidad territorial (Vidal y Pol, 2005; Márquez, 2008).

Estas materias resultan de gran interés al observar Villa Francia, ya que las prácticas conmemorativas que allí se desarrollan, son el resultado de un discurso identitario que adquiere una fuerte connotación espacial. En la población, son varias las fechas, los espacios y los sujetos de conmemoración. Si bien mediáticamente Villa Francia es conocida principalmente por las protestas nocturnas y enfrentamientos con fuerzas policiales, las prácticas conmemorativas son de una índole más diversa. La más comunes son los murales y rayados de textos, cuyos contenidos y consignas recuerdan tanto a los muertos y desaparecidos del lugar, como también a sus proyectos de sociedad. Luego, hay también actos de homenaje y actividades culturales (juegos deportivos, tocatas, actos discursivos, etc.) que se realizan durante el día y que en la mayoría de los casos involucran también el rayado de murales. Estas actividades ocurren fundamentalmente en seis fechas: 29 de marzo, también conocido como el Día del Joven Combatiente, y que nace en conmemoración a Eduardo y Rafael Vergara Toledo; 15 de julio, en homenaje a los Detenidos Desaparecidos; 5 de septiembre, para conmemorar a Miguel Leal Díaz; 6 de octubre, en conmemoración a Luís Silva Jara "Chaca"; 5 de noviembre, en homenaje a Pablo Vergara Toledo y 11 de septiembre, día que recuerda el golpe militar. En estas ocasiones, los actos de homenaje se encuentran asociados a marchas, romerías y murgas que transitan por la principal arteria de entrada a la Villa (Avenida 5 de Abril), las que en algunos casos finalizan con enfrentamientos nocturnos entre quienes participaban en los actos y carabineros.

\section{La identidad en la acción del discurso conmemorativo}

Villa Francia surge como el resultado de un contexto situado históricamente, en donde han jugado un rol importante la agresión dictatorial, el olvido transicional y la violencia en democracia. Si bien el discurso que sostiene las prácticas conmemorativas tiene su origen en la violencia impuesta por la dictadura militar, hoy en día se encuentra arraigado y revalidado a partir de visiones y lecturas críticas sobre la realidad actual.

Para los actores sociales que sostienen estos discursos, desde la dictadura hasta hoy, el sistema político es de continuidad, revelándose como social y económicamente injusto y opresor. Dentro de este marco, por 
ejemplo, se inscriben las muertes de jóvenes luchadores no sólo en dictadura, sino que también en democracia, es decir, se trata de una memoria por los muertos del sistema (conmemoración asociada fundamentalmente al Día del Joven Combatiente); por la lucha contra un Estado que no se hace responsable de la falta de acceso a servicios tales como educación y salud, así como también, de la falta de justicia frente a los eventos del pasado y del presente. En este sentido, en términos de contenidos no sólo se trata de una memoria post-dictadura distinta de aquella promovida por el Estado, en donde se rescatan las propuestas políticas de los muertos más allá de nombrarlos como víctimas; sino que también está la distancia existente con la visión oficial para comprender los procesos históricos, el presente, e imaginar los proyectos de sociedad futura.

Las condiciones políticas a partir de las cuales se instalan las memorias oficiales desde inicios de los ' 90 hasta la actualidad, y su fuerte cuestionamiento por parte de los actores que participan en las prácticas conmemorativas de Villa Francia, ha posibilitado el despliegue de expresiones de memorias propias, no sólo en los planos materiales y significantes, sino que fundamentalmente en las formas a partir de las cuales ésta se gestiona, proyectándose en el presente y hacia el futuro. En Villa Francia, la memorialización surge como un proceso auto-gestionado, en donde se reconoce, acepta y promueve la existencia de distintas memorias, resistiéndose a ser coaccionada por aquella -única- promovida desde la institucionalidad ${ }^{1}$. Ello es posible porque se trata de una memoria auto-consciente de su existencia y de su posibilidad de permanencia, por lo que reconociendo su origen en lo colectivo, requiere no sólo de actores que permeen los límites generacionales que permitan su difusión, sino que también la actualización de los objetos y sujetos de memorialización. Es dentro de este marco que surgen nuevos reclamos que se adhieren a las prácticas conmemorativas (ej. causa mapuche, el mejoramiento de la educación), y que ayudan a re-articular una memoria vida, con su propia identidad representada en un espacio también vivo. Este aspecto es de importancia a nivel de legitimación, ya que la revalidación y reproducción de los objetos y los sujetos de memorialización le da sentido al discurso, haciéndolo vigente en cualquier tiempo, independientemente de los cambios políticos ocurridos en el país. Ello asienta las bases para formular un proyecto social y político alternativo, que pareciera construirse de manera paralela a los poderes hegemónicos. Son proyectos propios que se recomponen desde la vulnerabilidad económica y social, y la marginalidad respecto del poder público; y dentro de este contexto, son proyectos auto-consientes de que no hay posibilidad de construir una historia en común.

Junto a la llegada del fin pactado de la dictadura, vino también el reconocimiento de la violencia política y de las violaciones a los derechos humanos cometidos por el régimen militar. Así también vieron la luz, las primeras comisiones de investigación de estas causas, la revisión judicial de los primeros casos y la implementación de políticas de reparación material y simbólica ${ }^{2}$. Es este cambio de escenario el que provocó tensión en algunas de las acciones que guiaban el proceso de memorialización en Villa Francia. La falta de sentencia judicial, o bien la inexistencia del proceso en los casos de los detenidos desaparecidos y jóvenes asesinados de Villa Francia ${ }^{3}$, ha posiblemente influido en el tipo de acciones que se llevan a cabo en la población, o al menos, en la visibilidad que éstas han tenido en los medios ${ }^{4}$. Respecto de las reparaciones materiales y simbólicas, cuando hubo acuerdos con la institucionalidad, si bien ello no conllevó cambios en el origen del discurso de la memoria, si impactó en las acciones, parte de las cuales tendieron a replegarse haciéndose más coherentes y funcionales con aquellas avaladas por el Estado. Ejemplo de esto es el desvanecimiento de los murales pintados en homenaje a los detenidos desaparecidos de la Villa, los que han sido reemplazados por un monumento memorial (si bien se siguen pintando murales por otras causas).

El discurso identitario en Villa Francia, se enmarca dentro de la existencia de una narrativa mayor, referida a los hitos fundantes de la población. Por una parte, la Villa se sitúa como una figura empoderada con alta capacidad de autogestión y de construirse a sí misma, lo que ha favorecido su fuerza organizativa y de dar respuesta frente a la contingencia. Ello también ha aportado en la consolidación de plataformas útiles al desarrollo de las prácticas conmemorativas, ya sea tanto a nivel de la incorporación de pluralidad de actores sociales, como de espacios ocupados. No es posible obviar el que tanto la fundación de la población (1969) junto a la existencia de una comunidad cristiana de base ${ }^{5}$ (1970), el inicio del gobierno de la Unidad Popular (1970) y, posteriormente el golpe de estado (1973), se desarrollaran no sólo en un muy corto período de tiempo, sino que además, que todo ello tuviese un fuerte impacto político, social y organizacional en la población. Así, el contexto histórico posibilitó la gestación de una narrativa fuertemente politizada, alimentada por la puesta en marcha de nuevos proyectos de sociedad (Unidad Popular), sus derrumbamientos 
(golpe militar), los reclamos de justicia (violencia de estado), la reflexión y crítica social sobre la contingencia, y las disputas y contestaciones frente al accionar del Estado. Es la apropiación de estos diversos referentes, en la continuidad temporal de los acontecimientos, lo que finalmente le ha otorgado sentido al discurso y su capacidad para ser reproducido, remontándose al origen del tiempo y repitiendo en el ritual de la lucha, las particularidades de la Villa desde su fundación. Así, la población se ha perfilado como un territorio donde acontecen eventos disruptivos al orden de la ciudad ${ }^{6}$. Las prácticas conmemorativas han adquirido todo su potencial narrativo, porque Villa Francia es el espacio donde la historia se construye desde allí, la memoria impugna y denuncia al presente, y el territorio se ejerce como la encarnación simbólica de lo político.

Finalmente, un aspecto importante para comprender el proceso de memorialización en la población, es conocer el discurso mediático en torno a la Villa, y las consecuencias que éste ha tenido en las prácticas conmemorativas que allí se desarrollan. Este discurso se ha centrado en dar a conocer sólo parte de estas expresiones -la protesta nocturna-, como hechos de violencia delictual, o bien, como promotor de ésta. De la misma manera, en términos de los contenidos que resultan del proceso de memorialización en Villa Francia, éstos han sido enmarcados como discursos enfermos e incapaces de incorporarse a la construcción de una memoria país ${ }^{7}$. Ejemplo de ello son expresiones que nacen desde el Estado y sus instituciones, y que juegan un importante rol para arraigar ciertos imaginarios en torno a la población: "los padres, familiares y amigos de los hermanos Vergara tienen todo el derecho a celebrar, recordar su muerte, pero no tienen ningún derecho a alterar el orden público ni poner en riesgo la vida ni la propiedad de las personas" (Sebastián Piñera, marzo del 2008) ${ }^{8}$, declaración que da contexto a que Villa Francia sea reconocido como "el sector que por años ha concentrado las miradas, y es allí donde se han producido los hechos más violentos" 9 , y se llevan a cabo las mayores estrategias policiales de prevención y de control en fechas emblemáticas ${ }^{10}$. Cuestión similar ocurre con otro anuncio que señala: "El alcalde Delgado, en declaraciones citadas por radio Bío Bío, comentó que (respecto de un supuesto incidente con carabineros en Villa Francia) "se habla preliminarmente de un arma de grueso calibre y se está investigando si es un fusil o si es otro tipo de armas" "11, situación que fue desmentida horas más tarde por representantes del gobierno. Bajo este escenario, resulta pertinente señalar que si bien existen acciones de protestas en el sector, la configuración de este tipo de relatos y su alta mediatización, ha generado una suerte de expectación cuyo fundamento se acerca más a una hipérbole de la realidad, que a una descripción contextualizada.

Este tipo de caracterizaciones tiene al menos dos consecuencias. Por una parte, alimenta la idea de la población como un sitio peligroso, violento e insurgente. Por otro lado, hace que todas las acciones que se lleven a cabo dentro del proceso de memorialización, sean observadas como ilegítimas y amenazantes al orden institucional. Más aún, en términos de contenidos, este proceso suele ser anunciado mediáticamente como marginal respecto de una memoria ya resuelta y apropiada por el Estado. De manera paralela, al interior de los grupos que participan en el proceso de memorialización, estos relatos mediatizados también tienen efectos: La estigmatización y los intentos de anulación de estos discursos, pueden suscitar la reactivación de las acciones penalizadas socialmente, pero que como fuerza de oposición se constituyen en mecanismos de fortalecimiento al grupo. En este sentido las acciones que se realizan tienen un carácter épico, alimentado en la propia historia de la Villa, en su fuerza y en su lucha. En el caso de las protestas nocturnas, por ejemplo, ellas se consolidan como una vía legítima en la medida en que han estado presentes desde los tiempos del origen de la Villa y han sido la expresión histórica de contestación al Estado. Cabe cuestionar, sin embargo, hasta qué punto las acciones de protesta no son sino el resultado de un diálogo en busca de legitimar el poder, ya sea hegemónico o contra-hegemónico. Es quizá dentro de esta trama, en donde cobran sentido la percepción de las violencias, sean éstas las llamas de las barricadas o la ocupación policial de las calles.

Para que el discurso narrativo pueda proyectarse y representarse, es necesario el uso de distintos productos y plataformas comunicativas (Reguillo, 1991). En Villa Francia, en algunos casos se trata de espacios puntuales, ya sea una muralla que se pinta recurrentemente o la referencia del sitio donde cayeron los muertos; en otras ocasiones son áreas territoriales más extensas y de límites difusos, como la Avenida 5 de Abril durante las protestas; y finalmente también la idea de un referente espacial abstracto, tal y como sucede con la idea de Villa Francia población contestataria (en la visión mediatizada). Estos espacios resultan de la materialización del discurso de los grupos de actores que participan en las conmemoraciones, y por otra parte, siendo ya referentes territoriales, estos espacios reafirman la capacidad comunicativa del discurso, proporcionándole una escenografía donde arraigarse. En este marco, las prácticas conmemorativas ayudan a la 
configuración en Villa Francia, de un espacio construido como extensión de la colectividad, ya que se trata de expresiones que adquieren una connotación territorializada.

De esta manera, las ceremonias, rituales y actos que ocurren en Villa Francia, hacen de todas las particularidades de este lugar, un rostro que se distingue de otras poblaciones y de otras narrativas identitarias. Así, además de las conmemoraciones, el territorio también es marcado y delimitado como una forma de denunciar, reafirmar e impugnar el control sobre el espacio, en particular aquellos que contienen mayor peso simbólico para el grupo. La capacidad de acción del discurso adquiere significación en la medida en que se encuentra arraigada al espacio de la Villa (físico y/o simbólico), ya que no sólo se trata de un lugar situado históricamente, sino que también situado espacialmente. Es allí donde la colectividad tiene su origen, en el evento; desde donde se potencia su capacidad organizativa; así como también donde tiene acceso a los soportes materiales en los cuales se exhibe el discurso (calles, murallas). Así, la ocupación del espacio de la Villa puede entenderse como una forma en la cual se valida su propia identidad.

\section{Los territorios simbólicos de la memoria}

El espacio es uno de los medios a partir del los cuales la memoria se organiza, expresa y transmite. En algunos casos éste cumple con la función de soporte de las distintas expresiones materiales que surgen del proceso de memorialización, en otras ocasiones, puede tratarse de sitios que sin dejar evidencias materiales permanentes, sostienen prácticas conmemorativas que se reiteran en el tiempo. En estas situaciones se ha posibilitado su consolidación como espacios simbólicos y en ellos han quedado incluidos y proyectados, los acontecimientos y rituales guiados por el proceso de memorialización. De acuerdo a Valera (1996) los espacios simbólicos son el resultado de una elaboración social y cultural asociada a los contenidos y significados simbólicos que estos son capaces de congregar y cuya valoración por parte de la colectividad, es representativa y útil a su discurso identitario.

En este contexto, se puede señalar que existe una relación significante, a la vez que funcional entre una comunidad y su espacio, marco dentro del cual tanto la identificación de los miembros a su grupo como su afiliación a un territorio, son fundamentales para componer la identidad (colectiva y territorial). Bajo este escenario, el espacio simbólico puede ser entendido como un depósito de significaciones (Vidal y Pol, 2005), que se va cargando en el transcurso del tiempo, y en este sentido se trata de una construcción de significados que son elaborados y reelaborados permanentemente. La relación de un grupo con su espacio se evidencia en la apropiación territorial, a partir de la cual la comunidad interioriza las características simbólicas del espacio, permitiendo reforzar la identidad colectiva y su identificación con éste. Serán a su vez, los "significados sociales vehiculizados a través de los espacios simbólicos [...] (los que facilitarán) la integración de nuevos sujetos a determinados entornos y tejidos sociales ya consolidados" (Valera, 1996: 80). De esta manera, la interrelación de una comunidad y su espacio, trasciende los aspectos físicos del entorno, e incorpora lo simbólico, ya sea mediante la construcción social de significados o la intervención material del espacio.

Esta relación entre colectivo y territorio, posibilita dotar a la narrativa de una base más estable para su desarrollo, tal es el caso por ejemplo, que Villa Francia adquiere significación por ser el sitio donde acontecieron los hechos -la muerte y la contestación frente el sistema político y económico-, a la vez que también se constituye en el espacio idóneo para que se despliegue la práctica conmemorativa. En la Villa, ello cobra especial trascendencia ya que además se ha consolidado como un referente para otras comunidades, tanto por el tipo de actividades que se desarrollan, como por la forma en la que se ha gestionado y revalidado la memoria. La reseña a la población trasciende el componente meramente locacional, fundándose como un espacio simbólico que resulta de la interacción entre la estructura físico-material, las acciones que allí tienen cabida, los actores sociales, sus deseos y sus imaginarios. No sólo se trata de replicar en cualquier sitio acciones y narrativas, sino de su escenificación en el espacio físico y simbólico que le da mayor significación a éstas. La ocupación de la población se constituye en sí misma en una acción conmemorativa no sólo de la narrativa identitaria, sino que del propio espacio, en tanto sujeto y símbolo de la memoria.

El espacio simbólico de Villa Francia, también se ha consolidado a partir de las imágenes de la población, ya sea las observadas directamente por la misma colectividad y los transeúntes, la transmitida por los medios de comunicación o la que es graficada en las murallas. La Avenida 5 de Abril junto a los bloques, 
sumada a los murales y a las acciones de protesta en esta avenida, es quizá la imagen más constante y vigorosa del espacio simbólico de la población. La narrativa identitaria requiere fortalecer su dimensión territorial, puesto que el significado simbólico atribuido a Villa Francia potencia su contenido discursivo, a la vez que también le da mayor riqueza y solidez simbólica, volviéndolo menos vulnerable. Dentro de este contexto, el valor simbólico de la población, asociado fundamentalmente al rol significante del proceso de memorialización, conlleva también un valor político.

Es en Villa Francia desde donde se impugna el poder hegemónico, y donde el reclamo se cristaliza en los muros y se inscribe en la memoria colectiva de los actores sociales locales, aunque ella suele ser negada por aquella promovida desde el Estado. Así, la población se consolida como un espacio político, resultado de la coexistencia de los modos de ser y hacer de narrativas identitarias en tensión, las que se manifiestan en acciones concretas tendientes a escenificar sus discursos, disputándose el espacio. Es bajo este escenario, y tomando las palabras de Di Masso, (2007) que "la protesta y la reivindicación localizadas despliegan una serie de mecanismos de arraigo y que no sólo incluyen formas visibles de territorialidad [...], sino que también narrativas y relatos del lugar que contribuyen decisivamente a nutrir el cuerpo de acciones que lo significan y transforman" (Ibid: 2). Son estas expresiones discursivas (materiales y no materiales) las que se consolidan como recursos para la labor retórica del espacio político. En Villa Francia, estas se traducen en prácticas conmemorativas que se inscriben en un espacio tiempo reiterativo, cargado de significaciones y símbolos.

El espacio, señala Massey (2005), es por naturaleza una zona de disrupciones que se construye desde la pluralidad y la multiplicidad que resulta de la coexistencia de distintas voces, cuyas trayectorias se entrecruzan e interactúan entre sí. Bajo este escenario, el espacio es un proceso de formación en el devenir del tiempo, a la vez que también es un producto de éste. La práctica política y conmemorativa que configura a Villa Francia, se funda en las voces de esas trayectorias: en lo que se dice, se cuenta y se hace, tanto como en las significaciones que les son asignadas. El espacio va dando cabida a todas estas voces que se despliegan desde sus propios pasados y huellas; y es la revalidación de éstas en el tiempo, lo que van llenando de contemporaneidad sus narrativas.

La práctica conmemorativa se funda en la repetición del calendario ritual de fechas emblemáticas, así como también en la marcación de aquellos territorios significantes para la colectividad. En ambos casos se trata de una forma de organizar el espacio y el tiempo, cuya particularidad es el intento de estar siempre presente. En tanto espacio político, la población se abre como una posibilidad de encuentro para dar cabida a otras memorias -voces y narrativas que circulan por la ciudad-, a veces marginales, extraviadas o censuradas, que no tienen otro territorio donde ser-hacer y encuentran allí un lugar donde adherirse. Villa Francia se torna así, en un territorio simbólico de otras memorias y luchas; donde se expresa el dolor de otras muertes en el tiempo; de la memoria que se reivindica, así como también la de aquella que no se reconoce a sí mismas como tal porque está llena de presente, más que de pasado. Las prácticas conmemorativas van incorporando nuevos aconteceres y protagonistas, tal y como ocurre por ejemplo, con la escritura en los muros de los nombres de jóvenes muertos en democracia, la presencia de sus familiares participando en los actos de homenaje, el dibujo de sus rostros o la incorporación de símbolos-íconos de las luchas del presente.

\section{Villa Francia, la retórica de la calle}

El espacio público suele estar controlado por el Estado, y es éste quien define cuáles son aquellos intersticios para exponer ideas o generar debates ciudadanos (Reguillo, 1996). La conquista de este espacio juega un rol importante para la construcción de las identidades, ya que posibilita la circulación de sus narrativas, y con ello quizá su permanencia. El control se ejerce principalmente por medio de los usos políticos del espacio público, en donde la presencia de la narrativa identitaria que ejerce el poder suele ser claramente visible, tanto a nivel material (con intervenciones), como simbólico (con significaciones). No obstante, entre los discursos institucionales, se abren paso aquellos que provienen desde los actores marginales, ya sea ocupando sitios a donde la autoridad no ha querido o no ha podido penetrar, o bien, irrumpiendo en aquellos donde se emplaza el poder hegemónico (por ejemplo, el centro cívico de la ciudad). Bajo este escenario, el espacio público se torna en un territorio en disputa de todas aquellas voces que conviven en la ciudad, y que reclaman para hacerse escuchar. Se trata por tanto del espacio idóneo para el desarrollo de la movilización e interpelación política. 
Reguillo (1996) reconoce diferencias entre los usos políticos que el Estado hace del espacio público, de aquellos que provienen desde la sociedad civil. Los primeros suelen generar espacios regulados y controlados, en donde se emplazan elementos rituales propios de la identidad nacional, o bien vinculados al ejercicio de su poder (por ejemplo, los monumentos a los héroes de la patria). Distintamente, la sociedad civil hace un uso político del espacio público marcado por la irrupción, principalmente como mecanismos de protesta y de denuncia contra el Estado. De acuerdo a la autora, estos suelen desarrollarse en la calle o en las plazas, y al ser espontáneos tienden a ser "imaginativos e innovadores, proponiendo elementos simbólicos alternativos, más fuertes en eficacia" (Ibid: 330). Esta distinción resulta útil para observar las particularidades de Villa Francia respecto de la ocupación de la calle por los grupos que participan en las conmemoraciones, ya que su territorio se ha determinado y organizado por actores locales y no por la autoridad. Se trata del uso político de la calle a partir de elementos rituales cuya significación ha sido reinventada para crear marcos simbólicos que ayuden a afianzar su discurso. Estos elementos son de diversa índole, involucrando los rayados en los muros, los homenajes litúrgicos, así como por ejemplo también el acto de compartir el vino y el pan, que se ha trasladado desde la misa al homenaje en la calle, y que cumple con el objetivo simbólico de reunir bajo una misma acción a toda la comunidad que conmemora ${ }^{12}$.

Respecto de la ocupación del espacio público, desde la lectura externa realizada por la autoridad, las actividades que se desarrollan en la Villa suelen ser consideradas como irrupciones insurgentes. Distintamente para la colectividad, el uso y la ocupación del espacio público para la práctica conmemorativa es considerada como expresión legítima, en tanto que la llegada de la autoridad a la Villa es leída como el elemento provocador. Es en el cruce de estos dos discursos desde donde nace la disputa por el derecho de ejercer el dominio sobre el espacio de la calle. El uso del espacio público como sitio para la interpelación de distintas narrativas, es un signo político que implica el paso de un problema desde la lógica privada a la lógica pública (Reguillo, 1996). La movilización del espacio de discusión, hace que el debate se democratice, o que al menos su contenido se abra y exponga a los ciudadanos. Dentro del marco del proceso de memorialización en Villa Francia, la comunidad se manifiesta tanto para reclamar justicia, como para reivindicar proyectos y sujetos, visibilizar la memoria colectiva, así como también evidenciar los vínculos simbólicos que el grupo tiene con ese territorio. Toda memoria requiere de un marco espacial que le dé sentido, y en el caso de Villa Francia este espacio es la calle. Es el territorio constituido por el conjunto de arterias que conectan la población, los muros exteriores de casas y cierres que delimitan el paso hacia lo público, las historias allí vividas y contadas, los recuerdos inscritos y todos aquellos símbolos y significaciones que dan cuenta de su apropiación.

En Villa Francia, la calle se presenta como un soporte identitario importante, es aquí donde se organizó la vida cotidiana de la población y ocurrieron los acontecimientos más importantes, es también donde se gestó y desarrolló la vida política y la práctica conmemorativa. Desde su origen el año 1969 con el trazado autogestionado de la población, distribución de pasajes, calles, áreas verdes y marcación de la ubicación de los posibles servicios, se da la idea de proyectar una vida que está fuera del ámbito privado y se interna en la lógica comunitaria de los espacios y vidas compartidas. Igualmente ocurre con los desafíos afrontados para mejorar las condiciones de vida de la comunidad y cuyas batallas y conquistas se hicieron en la calle, tales como la obtención de pavimento o de transporte público en los años ' 70 , como la mejora de este servicio o la instalación de semáforos 35 años después. Durante la dictadura la calle fue testigo y contenedora de los asesinatos expuestos en la vía pública, de la desaparición de pobladores frente a los ojos de sus vecinos, y de la violencia ejercida hacia el cotidiano habitar con allanamientos y toques de queda. En este período, los actos de invasión hacia la población y sus habitantes, fueron también actos de invasión a lo más íntimo y lo más comunitario. Dentro de este marco, la reivindicación de la calle como lo propio, es decir "la calle es mía", "la calle me pertenece", se constituyó en un acto de resistencia política, del ejercicio de la soberanía de la colectividad y de su reafirmación identitaria. Es este mismo discurso, igualmente, el que se replica hoy en día frente a la intervención policial en la Villa, durante flechas emblemáticas.

Consecuentemente con la reivindicación de la calle, es el uso y apropiación de este espacio el que logra congregar los discursos y lógicas de acción que sostienen el proceso de memorialización. Por una parte, es el escenario donde la memoria toma lugar, arraigada a sitios singulares donde acontecieron sucesos de significación. En este sentido, es el espacio vinculado a un evento el que evoca a la memoria: es el sitio donde cayeron muertos los hermanos Vergara Toledo, Luís Silva Jara y Miguel Leal Díaz. Por otra parte, la estructura físico-espacial de la calle sirve de vehículo o soporte de la memoria: las animitas y los actos de 
homenaje, así como aquellas murallas donde se rayan las consignas conmemorativas. Finalmente, la calle también es el contenido de la memoria, y cobra vida en ella porque su ocupación es parte de la práctica social de recordación. Es en la calle donde los muertos y sus proyectos sociales han sido continuamente reclamados, y por ello es considerada material y simbólicamente como un territorio de lucha y resistencia, ganado a fuerza del saber-ser y saber-hacer. Así por ejemplo, la calle es parte integrante de prácticamente todas las lógicas de acción conmemorativas que ocurren en la Villa, ya sean actos culturales, de reivindicación o de protesta. La calle es en sí misma uno de los objetos de memorialización de las prácticas conmemorativas, ella les recuerda a los actores sociales quienes son, a la vez que los amarra al territorio de la Villa.

La disputa y la confrontación, tanto como la memoria, la reivindicación y la recordación de los muertos, forman parte de una narrativa, que en Villa Francia adquiere una dimensión territorial que se expresa en la calle. Las prácticas conmemorativas, potencian la labor retórica de este espacio que se va llenando de contenidos que interpelan a los transeúntes, invitándolos a adoptar una actitud, un pensamiento o una acción. La escritura de murales y consignas, es una de las principales prácticas que se desarrollan en la Villa, y se constituye como una expresión característica que sitúa al discurso conmemorativo en la escena pública. La calle es una escuela que enseña discursos y que invita a reflexionar; más aún, deja claridad que es aquí el lugar donde lo político debe llevarse a cabo. Trascendiendo la escritura sin embargo, la principal cualidad retórica de estas inscripciones es que configuran una escenografía propia, quizá, el paisaje arquetípico de la contestación o de la leyenda urbana de la insurgencia. Por otra parte, los cuerpos de los muertos, ya sean inscritos en los muros o evocados en los discursos, constituyen un lenguaje de persuasión para adherir a la narrativa identitaria, cuyas expresiones más importantes dentro de la práctica conmemorativa se desarrollan igualmente en la calle.

Además de las escrituras y los actos, las romerías y marchas también asientan el domino de la comunidad en el espacio público. Esta práctica conmemorativa en movimiento, se configura como una suerte de peregrinaje, es decir el tránsito como expresión de devoción, haciendo del espacio profano de la calle, un espacio sagrado. La calle se torna en el templo, marcado por la reiteración del itinerario, por la presencia de la comunidad devota, así como también esta cualidad es sostenida por diversas acciones y objetos mediadores: La pancarta, la vela, las flores, el panfleto y el grito, son parte de los ritos que marcan el inicio, la trayectoria y la llegada del peregrinaje, edificando espacios de significación. Sin embargo, es la cualidad simbólica de las calles de Villa Francia, en tanto espacio de lucha y de conquista, desde el pasado y hacia el futuro, y la posibilidad de la construcción cotidiana que confiere el movimiento, lo que les otorga la ocasión de consolidarse como un espacio sagrado.

De la ocupación de la calle durante las marchas y romerías que se realizan en Villa Francia, es posible destacar dos aspectos. Primeramente, la ocupación y desplazamiento por la calle de un grupo de personas y, las diversas acciones y objetos mediadores que lo acompañan, impregnan el espacio público de un acontecimiento ritual. Este cumple con el rol de comunicar y reafirmar al colectivo que realiza el trayecto, a la vez que también se muestra y enseña a los otros, sus discursos, reclamos y proyectos, haciendo de la calle un espacio para la discusión política. Seguidamente este acto de ocupación, es también una forma de tomar posesión de la calle. Es un gesto hacia la autoridad, y al propio colectivo, que por una parte recuerda su derecho soberano a expresarse; y por otro lado, redefine el límite de lo permitido, marcando una frontera territorial entre la comunidad y la autoridad. En este caso, la calle es un espacio de intervención política. Tanto el primer y segundo aspecto, resaltan la acción que se desarrolla como una voz que quiere hacerse escuchar, no sólo por la autoridad, sino que principalmente porque es una forma de involucrar e invitar a los vecinos. En este sentido, si bien las ceremonias potencian la cohesión interna del grupo, ya que tienen un carácter íntimo determinado por el sentimiento de acompañamiento y de adhesión sentida; por otro lado, su acción en bloque también constituye un rostro externo de gran capacidad enunciativa a quienes observan desde afuera.

Dentro del marco de los actos conmemorativos que involucran desplazamientos, es pertinente detenerse en aquellos que involucran la protesta nocturna-los más mediatizados-. En este caso la ocupación de la calle tiene por objetivo poder asentarse y no transitar por ella, como ocurre con las marchas y romerías. Este acto, sumado a las acciones para obstaculizar el flujo vehicular lleva a la práctica el discurso de tomar posesión de la calle y desafiar a la autoridad. Estas actividades tienen orígenes más complejos y antiguos que las marchas y romerías, remontándose a las acciones que se desarrollaban como expresión de rechazo a la 
dictadura militar. Posteriormente, se siguieron realizando dentro del marco del reclamo frente a cuestiones contingentes, o bien, dentro del contexto de fechas emblemáticas. Durante estas ocasiones además, suele existir la intervención de la fuerza pública, cuestión que completa el cuadro de provocaciones y desorden bajo la figura de la protesta nocturna. Cabe señalar sin embargo, que parte de estos eventos suelen ser el resultado de la interrupción de actos públicos, por parte de carabineros, cuyo resultado es la confrontación en la calle.

Las calles de Villa Francia se configuran como el espacio de una forma de manifestación, que desde la mirada institucional pareciera desbordar la práctica conmemorativa permitida y legítima. En este sentido, para el establecimiento del orden es necesaria no sólo la canalización de la memoria hacia las formas, contenidos y estructuras de gestión avaladas por el Estado, sino que también evitar su exposición en el espacio público, ya que es aquí donde se corre el riesgo de que ella se torne materia de debate y de enseñanza política. Es una tarea difícil, porque el mayor problema es quizá, que desde la Villa no sólo se trata de la conmemoración, sino que de una forma de habitar su población -y por qué no la ciudad-cimentada en la calle.

En Villa Francia, pese a todos estos cambios que evidencian el transcurrir del tiempo, pareciera ser que en varios aspectos todo continúa inmutable: la memoria, las luchas libradas y las que quedan por librar. Esta inmutabilidad aparente sin embargo, se debe más a la permanencia porfiada de estos aspectos a lo largo del tiempo, que a la perpetuación de sus contenidos. Bajo este escenario, es coherente que al menos parte de las lógicas de acción que sostienen estas narrativas tengan directa relación con prácticas conducentes a la recuperación de espacios públicos. Estas acciones, haciendo uso de una frase de Di Masso (2007) pueden ser entendidas como "reivindicaciones en defensa del espacio ocupado [y] se basan, al menos en parte, en el significado emocional o simbólico que representa tal espacio para un nosotros (los defensores de la autogestión)" (Ibid: 12). En ocasiones, cuando se ha forzado la barrera para marcar los cambios, señalando que la comunidad que conmemora ya no es la misma, ni que tampoco lo son las causas de lucha, ni el Estado, ni sus acciones o mecanismos de intervención; entonces, las lógicas de acción de los grupos que sostienen el proceso de memorialización, encuentran otras formas para expresarse o reivindican las antiguas, y junto con ello trazan nuevas territorialidades que le dan sentido a su discurso. Se pintan y restauran murales, se ocupan las mismas calles, el acto se realiza en la plaza de siempre, se utilizan mecanismos virtuales de difusión, se repite el discurso en otros actos y se incorporan nuevas causas de lucha.

\section{Consideraciones finales}

El proceso de memorialización en Villa Francia se ha construido desde los tiempos en que ocurrieron las primeras muertes y las violencias, registrándola en los muros aún antes de que se reconociera el terror de Estado. Así también, surge como concientización política, en la reflexión y crítica social, cuando estaba prohibido dar cabida a estos discursos. Pareciera ser que lo que Villa Francia quiere narrar, siempre ha estado visible. No sólo hace cuestionarse a los sujetos acerca de las verdades históricas, sino que su proceso de memorialización también se traza como una interpelación a la contingencia del presente. Si en los proyectos institucionales la memoria se somete a su pasado para servir de ejemplo al futuro, en Villa Francia la experiencia del pasado enseña a comprender el presente, y es el presente que se construye hoy -en la lucha-, el que puede otorgar la posibilidad de tener un futuro. En este sentido, la memoria no se subordina a su pasado sino que a su presente, y el pasado se configura como parte del cimiento que ayuda a construir y a legitimar su identidad.

El discurso nace de la marginalidad política, social y económica, así como también desde el olvido y el aislamiento de una justicia social que nunca llega. Nace igualmente de la experiencia de haber sido aplastado pero no derrotado; de haber recibido la muerte sembrada sobre él, sin haber logrado su extinción. Es por tanto un discurso sobreviviente, que reconoce que su única posibilidad de existencia es fundarse sobre sí mismo. En este sentido, no busca apoyos externos ni mediaciones, sino que se recrea en lo que ya conoce, su propia historia y experiencia, y es sólo a partir de allí, desde donde el discurso se divulga y expande. Para poder visibilizarse -objetivarse y legitimarse- el discurso se torna en práctica conmemorativa, y en este proceso la calle juega un rol fundamental. De todos los espacios significantes, la calle es el primer ámbito que le otorga espacialidad al discurso. Su ocupación es el principal esfuerzo de resistencia frente a la memoria institucional y al Estado, es sacar la política a la calle con la cuota de conflicto justa para poder llamar la atención, y hacer de este espacio, un lugar de debate. En su disputa contra el tiempo y el olvido, todo lo que involucra el 
proceso de memorialización queda inscrito en el espacio de la calle. Ésta da cobijo a las conmemoraciones: las escrituras públicas, las marchas, los actos y las aclamaciones. Así también, en la calle se despliegan las voces reivindicativas, audibles y textuales, que se entremezclan con el cuerpo colectivo de la comunidad.

Las diversas prácticas conmemorativas y reivindicativas que se han ido desarrollando en Villa Francia, han producido y configurado su propio proceso de memorialización: auto-gestionado, incorporando el aprendizaje del pasado, pero observante, crítico y actuante frente a la realidad presente. Villa Francia surge como un paisaje de la contestación, aquel donde se inscriben consignas en las murallas reclamando justicia, donde los jóvenes que cayeron en dictadura participan en las disputas de hoy ${ }^{13}$, así como también donde se recrean acciones de lucha que responden críticamente al rol del Estado. Por otra parte, Villa Francia es igualmente el espacio mítico de las luchas contra la dictadura y el reclamo de justicia en democracia; desde donde los muertos nunca partieron y siguen poblando el espacio, porque sus proyectos continúan allí, vigentes. Es asimismo el espacio simbólico de los territorios que no han podido ser domesticados. Finalmente, Villa Francia se consolida en el lugar que convoca y contiene a los padres de jóvenes asesinados en democracia, a las colectividades que reclaman causas marginadas por el Estado, y en muchas ocasiones a quienes por breves instantes reclaman por un problema político y social contingente.

La aclamación ¿Quién lucha con arrogancia? ¿Villa Francia!, que se escucha en los distintos actos públicos de la población, y se escribe en textos reivindicativos y ocasionalmente en las murallas, es también la soberbia de aquel que se reconoce a sí mismo en su propio territorio, nunca regalado, sino que ganado en la calle, en la conquista de cada día y en la lucha contra el adversario ${ }^{14}$. Habla también de la permanencia que el sujeto Villa Francia ha podido establecer en el tiempo, haciendo uso de la calle para comunicar quién es y decir que sigue allí. La población reconoce el peso de su propia figura en las batallas libradas y se jacta de ello, porque sabe por experiencia que si la calle es el espacio simbólico de sus luchas, ella misma -la Villa-, se ha consolidado como el espacio simbólico de las luchas que se libran en la calle. Así, Villa Francia es a la vez acción y representación, la dimensión material y simbólica de un territorio que irrumpe en la ciudad.

\section{Notas}

${ }^{1}$ Esta situación es distinta de lo que puede ocurrir con la oficialización de otras memorias, que naciendo desde la resistencia, se insertan dentro de la institucionalidad, tal y como por ejemplo ha ocurrido con los sitios de Londres 38 o Villa Grimaldi.

${ }^{2}$ Entre las comisiones de investigación, está la Comisión nacional de verdad y reconciliación creada el año 1990 (Comisión Rettig) y la creación de la Comisión nacional sobre prisión política y tortura el año 2003 (Comisión Valech). Las reparaciones materiales se centraron en ayudas monetarias, pensiones, becas y beneficios de salud. Entre las reparaciones simbólicas se encuentran principalmente las obras memoriales.

${ }^{3}$ A modo de ejemplo se señala que la muerte de Pablo Vergara Toledo nunca ha sido aclarada, al igual que la muerte de Luís Alberto Silva Jara. En el caso de Eduardo y Rafael Vergara Toledo la sentencia de asesinato se dictó el año 2010, después de 25 años de ocurrido el hecho.

${ }^{4}$ Hasta el año 1994, fecha en que ocurre el cierre judicial del Caso Degollados (se trata de Santiago Nattino, José Manuel Parada y Manuel Guerrero, asesinados el mismo año y día que los hermanos Vergara Toledo), este acontecimiento aparecía -al menos en los medios- como el eje de las manifestaciones ocurridas en las cercanías de los días 29 de marzo. No obstante, a partir de 1994 el centro se transfiere con mayor claridad hacia Villa Francia y los hermanos Vergara. Ya en esa fecha, se había hecho conocido el Día del Joven Combatiente.

${ }^{5}$ Surgen hacia la década de los 70 y estaban a cargo de sacerdotes obreros. La idea de las comunidades era que pudiesen autogestionarse y estar a cargo de los propios miembros y no de un sacerdote.

${ }^{6}$ Se señala como ejemplos las conmemoraciones en fechas emblemáticas tales como el 29 de marzo (día del joven combatiente), el 11 de septiembre (día del golpe militar), así como también acciones que se concretan durante convocatorias a protestas nacionales, o bien en eventos de específicos de réplica social y política, como por ejemplo durante la puesta en marcha del Transantiago.

\footnotetext{
${ }^{7}$ Se hace referencia aquí a lo propuesto por Rancière (2005), en donde el paso de la comunidad política a la comunidad ética, ha provocado que actores sociales antes conflictivos para la visión de los poderes hegemónicos, hoy sean simplemente considerados como enfermos, o como denomina el autor, el otro radical.

${ }^{8}$ Declaraciones del Presidente Sebastián Piñera el 28 de marzo del 2010, en una visita a la Prefectura de Fuerzas Especiales en Santiago. Este año en particular, una dotación de 4.000 de estos funcionarios salieron a las calles de Santiago, como prevención a eventuales manifestaciones.
} 
${ }^{9}$ Noticias en el canal abierto Chilevisión, el 29 de marzo del 2010.

${ }^{10}$ El 29 de marzo del 2010, los noticieros de Chilevisión y TVN, mostraban al alcalde de la comuna explicando los operativos de seguridad (controles de identidad, y cámaras de seguridad). A su vez, el presidente de la República señalaba sobre el operativo: "Con «toda la fuerza del mundo» y con «todo el rigor de la ley». Así enfrentará el Gobierno al denominado «Día del Joven Combatiente" (www.emol.cl, del 29 de marzo del 2010).

${ }^{11}$ Noticias en línea en www.lanación.cl, del 30 de marzo del 2010.

${ }^{12}$ Ejemplo de estas actividades ocurren en el acto de homenaje a los detenidos desaparecidos o en el acto de homenaje a Eduardo y Rafael Vergara Toledo.

${ }^{13}$ Se señala a modo de ejemplo un rayado de octubre del 2011, de cerca de 120 metros de largo y 2 metros de alto, en homenaje a Luís Alberto Silva Jara, en donde se leía "Chaca niño asesinado por los pacos, estas presente en cada estudiante rebelde que lucha por una educación digna".

${ }^{14}$ Se entiende acá lo definido Benjoit (2003), el adversario es a quien se le atribuye la responsabilidad de lo que ocurre. En el caso de Villa Francia es el Estado, instituciones de seguridad, y en gran medida también la prensa.

\section{Bibliografía}

Bajoit, Guy, (2005), Todo cambia. Análisis sociológico del cambio social y cultural en las sociedades contemporáneas". Colección Escafandra, LOM Ediciones, Santiago de Chile.

Bengoa, José, (2011), Identidad: La evolución de las miradas, consultado en junio del 2011 en www.identidades.cl/identidades $11 / ? \mathrm{p}=526$

Di Masso Tarditti, Andrés, (2007). "Usos retóricos del espacio público: la organización discursiva de un espacio en conflicto". En: Athenea Digital, número 11, páginas 1 - 22. Universidad Autónoma de Barcelona, Barcelona, España.

Márquez, Francisca (2008), “Deseos e identidad en disputa. Santiago de Chile: 1958 - 2008”. En: Revista Chilena de Antropología Visual, número 12, diciembre 2008, páginas 147-170. Revista Electrónica de la Universidad Academia de Humanismo Cristiano, Santiago, Chile.

Massey, Doreen (2005), "La filosofía y la política de la espacialidad. Algunas consideraciones", En: Arfuch, Leonor (compiladora), 2005, Pensar este tiempo. Espacios, afectos, pertenencias. Editorial Paidós SAICF, páginas 101-127, Buenos Aires.

Reguillo Cruz, Rossana (1991), En la calle otra vez. Las bandas: identidad urbana y usos de la comunicación. Instituto Tecnológico y de Estudios Superiores de Occidente (ITESO), México.

Ídem, (1996), La construcción simbólica de la ciudad. Sociedad, desastre y comunicación. Universidad Iberoamericana e Instituto Tecnológico y de Estudios Superiores de Occidente (ITESO), México.

Valera, Sergi, 1996, “Análisis de los aspectos simbólicos del espacio urbano. Perspectivas desde la Psicología Ambiental" En: Revista de Psicología Universitas Tarraconensis, 18 (1), páginas 63-84, Universidad de Barcelona, Departamento de Psicología Social, Barcelona, España.

Vidal Tomeu y Pol Enric, 2005, "La apropiación del espacio: una propuesta teórica para comprender la vinculación entre las personas y los lugares”. En: Revisa Anuario de Psicología, volumen 36, № 3, páginas 281297. Facultad de Psicología, Universidad de Barcelona, Barcelona, España.

$$
* * *
$$

Recibido: 15.02 .2012

Aceptado: 11.03.2012 